\title{
Proposed Strategy in Teaching Design Fundamentals for Understanding the Relationship between Idea and Idea's Projection
}

\author{
Donia M. Bettaieb \\ Interior Design and Furniture Department, King Abdul-Aziz University, Jeddah, Saudi Arabia \\ Email: doniamalek2@gmail.com
}

How to cite this paper: Bettaieb, D. M. (2017). Proposed Strategy in Teaching Design Fundamentals for Understanding the Relationship between Idea and Idea's Projection. Art and Design Review, 5, 129140.

https://doi.org/10.4236/adr.2017.52010

Received: February 16, 2017

Accepted: May 19, 2017

Published: May 23, 2017

Copyright $\odot 2017$ by author and Scientific Research Publishing Inc. This work is licensed under the Creative Commons Attribution International License (CC BY 4.0).

http://creativecommons.org/licenses/by/4.0/ cC) Open Access

\begin{abstract}
During foundation stages, interior design students are faced difficulties in mental perception of the relationship between matching two-dimensional drawings and expressive design ideas, especially when designing compositions and building relationships between design elements. The purpose of this study is to determine what is the teaching strategy that enables students to perceive relations between ideas of design and their foundations of projection during the foundation stage? The researcher has come up with basic steps enabling students to project their design's ideas easily. Each stage of these stages is dependent on self-assessment criteria, certified as a reference, to be assigned to students and allow them to link the theoretical findings with practical work. The purpose of this study is to determine what is the teaching strategy that enables students to perceive relations between ideas of design and their foundations of projection during the foundation stage? The researcher has come up with three basic steps enabling students to project their design's ideas easily, and gradually perceives the concept of building relationships between the design's idea and foundations of their projections in the foundation stage. These steps are represented in the stage of sketching the composition prior to their embodiment (cutting paper template), the stage of alternate adjustment of embodiment and sketching, and finally the stage of sketching composition after their embodiment.
\end{abstract}

\section{Keywords}

Design, Teaching, Strategy, Studio, Sketching

\section{Introduction}

Foundational stage refers to the overall design, and it is usually associated with 
the first year in the field of specialization after the preparatory year (if any) in the Higher Education System. The mentioned stage requires a set of knowledge, concepts and basic specialized skills that are the foundation to build a feature filmmaker education programme as a whole. And it turns out Gencosmanoglu and others said that this first year could be defined as an adaptation period for students, in this period, the students get the specialized knowledge, in addition to the physical and social environment. They also learn during this period a number of concepts and skills representing a set of profession conduct rules (Gencosmanoglu et al., 2011).

From this perspective, the educational process facilitates and allows within its theoretical foundations during the very first stages, the students to learn main elements, principles and methods of design in order for them to know how to implement them, produce innovative graphic arts and express them through drawings or modellings during practical application.

The educational process during the foundation stage, regarding the design specialty in general, and interior design in particular, has a huge importance, especially given the role being played by it in forming students' visions, their acquisition of main specialty skills and knowledge, and generally their discovery of the specialty philosophy and its foundations. It is worth noting here that whatever the academic program being accredited in this specialty is (Program hours' number, its objectives and the nature of outcomes), the educational process, on one part, is based on theoretical foundations, and on other part, it is based on practical application through which students could learn design, and intensively prove their creative abilities, in which it tackles how to communicate, hold discussions and gain knowledge (Ustaomeroglu, 2015). The foundation stage should train the students to improve their ability to think and solve problems instead of peacekeeping information only. It should help them on improving their skills to work as a future designer.

With all these main necessities, educational strategies adopted by the academic staff are deemed to be of special importance during the foundation stage. Wang has explained this when he insisted on the necessity to change the way being followed by professors of design in expressing the theory of knowledge and its methodology (Wang, 2010). Educational strategies should build student characters, student responsibility, and self-monitoring. The students are aware of their ability to cope with the specialization of their personalities and their ability to develop.

For defining or changing such methods, educational strategies adopted by the academic staff during the foundation-stage should define two main components that have been discussed by Zaytoun, in methods and procedures (Zaytoun, 2000), in addition to the necessity of making a plan relying on a set of systematic steps that may help reaching goals of the stage, and ensuring the quality of educational outcomes, with complete exclusion of the classical teaching method, as mentioned by Tavsan \& Sonmez. Both of them have explained that the classical teaching method which depends on the instructor (Teller) and the leaner (Lis- 
tener), is applied in different fields. However, in the interior architecture field, concepts like vision, cognition and knowledge are far more influential than the classical teaching method which concentrates on verbal expression by instructors, and listening by students (Tavsan \& Sonmez, 2012), considering the necessity of skills and knowledge acquisition enabling students to share their ideas and proposals in a creative way.

Orthel \& Day said that interior designers usually express their ideas through drawings and other various communication forms, while the beginners often face obstacles in delivering their ideas (Orthel \& Day, 2016), since they have not yet acquired a set of empowering knowledge and skills.

Due to the absolute difficulty in determining a method(s), or procedure(s), to teach the foundation stage in the design field, in general, and interior design, in particular, we basically can set theoretical foundations and practical application levels, aiming at training students during their first year, to learn design through illustrating the most important goals of the stage.

As the foundation stage intends-in design specialty generally, and interior design particularly - to build students' ideas, knowledge and skills; as follows:

- Development of specialized knowledge: Through simplifying concepts related to principles and elements of design, in general, and interior design, in particular; further development of cognitive skills related to principles such as; rhythm, balance and repetition in relation with Anthropometry and Ergonomics, and the group of methods enabling them to produce a creative design in conjunction with the design's elements (dot, line, shape, color, space, shadow and light.)

- Development of self skills: Which should be acquired, at a minimum, in the design specialty field, in general, and interior design, in particular, given that the idea of design requires a sound thinking and methodology along with proper drawing foundations enabling students to completely deliver their ideas. The most important skills are; expressive, engineering drawing skills, communication skills and the ability to hold responsibility.

- Creating a creative and critical thinking: Provisional thinking is needed during building and developing the idea of design contributing in students' creativity and innovation.

In this context, the style or method used in building the ideas, knowledge and skills of the student are one of the most important data achieving the efficiency. In addition, there are correct methods that can be used in the studio, especially in the foundation stages of teaching design, including finding answers to the questions of "what is the problem?" and "what is the solution for the problem?". According to the instructions of the teacher in order to reach solutions for the design through the discussion and conviction not through receiving and applying the solutions (Ustaomeroglu, 2015).

\section{Research Approach}

The research is based on the descriptive analytical approach to describe and 
analyze steps of teaching the bases of design (elements, principles, methods, composition, and organization). In addition, the research used the empirical approach-practical and procedural-through observation and writing down the steps of applying the work strategy, besides verifying the outcomes of each stage.

The study has been applied through the following two stages:

A-The stage of planning for study and defining the necessary data

- Define the duration (4 weeks).

- Define the academic material/the content of the training/objectives/evaluation standards/educational objectives.

B- The stage of activating the planning and following up the steps

- Observe and write down the most important difficulties that face the students.

-Verify the outputs for each step.

In this second stage, the researcher has identified 3 steps to reach the educational target. It's considered as a scheme intending to make student able to manage the designing process. The 3 steps have been specified as follows:

- From sketching to the embodiment.

- Alternate adjustment of embodiment and sketching (cutting paper template).

- From embodiment to sketching.

However, in this second stage, the researcher didn't reach to the desired outcomes in the first step, so she directed to the second step to clarify the concepts and then to the third step in the form of repeating the requirements of the first step, and then she reached to the desired objectives.

\section{Population and Sampling}

The target participants of this study included 31 female students who were chosen as a sample representing all the students of the two sections enrolled in the course of first interior design studio at Faculty of Home Economics, Housing Department, Interior Design and Furniture Program, third level at King Abdul-Aziz University in Jeddah, Saudi Arabia. The course of first interior design studio was applied in the first semester 2016.

Date was collected through observation and recording the steps of applying the work strategy, besides verifying the outcomes of each stage.

\section{Results and Discussion}

The strategy of teaching in the foundation stage includes set of procedures selected in advance by a member of teaching staff that will use them during teaching, which will achieve the desired objectives effectively according to the available possibilities. In this order, the teaching objectives of the foundation stage shall be defined according to the procedures reflecting the stage in which the mental growth of the student and individual differences are respected.

In this context, the student finds himself, at the beginning of the area of specialization, as being able to:

- Understand all the new knowledge and concepts to adopt them as the basis 
of his ideas and building the creative thinking.

- Acquire the minimum of two and three-dimensional drawings to adopt them as the mean for expressing the ideas and innovative designs.

- Interact with new educational style of the studio different from the usual educational style of the background studies. Because students begin the processes of stepping to thinking, editing, creating and expressing after high school education based on memorization and repetition (Ustaomeroglu et al., 2015). The studio is also different from the rest of specialized courses. It depends on building the critical and creative thinking and the vision and personality of the student in the area of specialization.

- Produce the design idea in which several gradual data and objectives react together to reach a result reflecting a private respective.

\subsection{Classification of Teaching Methods}

Teaching strategy in the education process for the primary education is divided into two categories which are theoretical and practical as shown in $\mathrm{Ta}$ ble 1.

The researcher determined the target for the first stage in forming the student's "vision". This target appears when the student is able to create relations between designing elements and reaching expression through composition designed about the first choices of the designing principles which were determined and approved in the beginning of the designing process.

The designing process steps were Determined in this trend in spite of the variety of data and exercises that added to train the students according to the following Figure 1.

\subsection{Foundation Stage Steps}

Researcher designs the following Table 2. to determinate the flexible steps followed to reach the educational target. It's also considered as a scheme intending to make student able to engage in the vision and target of the primary stage and prepare his psychologically to manage the time and designing process.

\subsection{Difficulties}

Based on the previous steps of the foundation stage, the difficulties are written down through observation and the models of the outputs of each stage were defined as shown in Table 3.

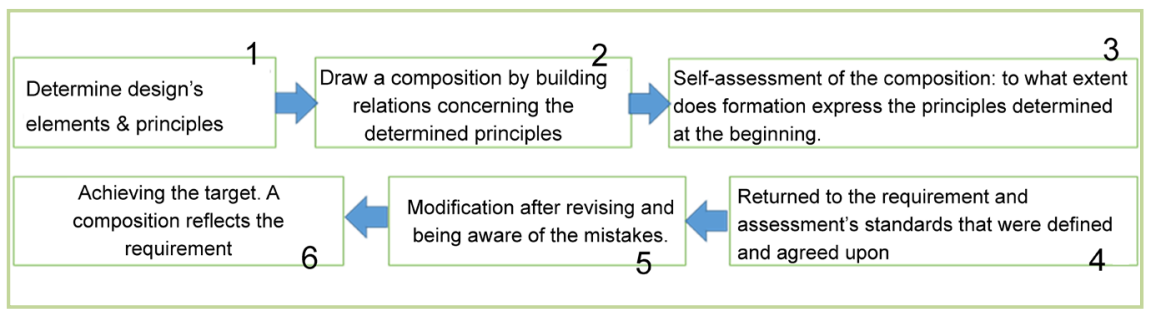

Figure 1. Defining designing process steps. 
Table 1. Theoretical bases and practical working.

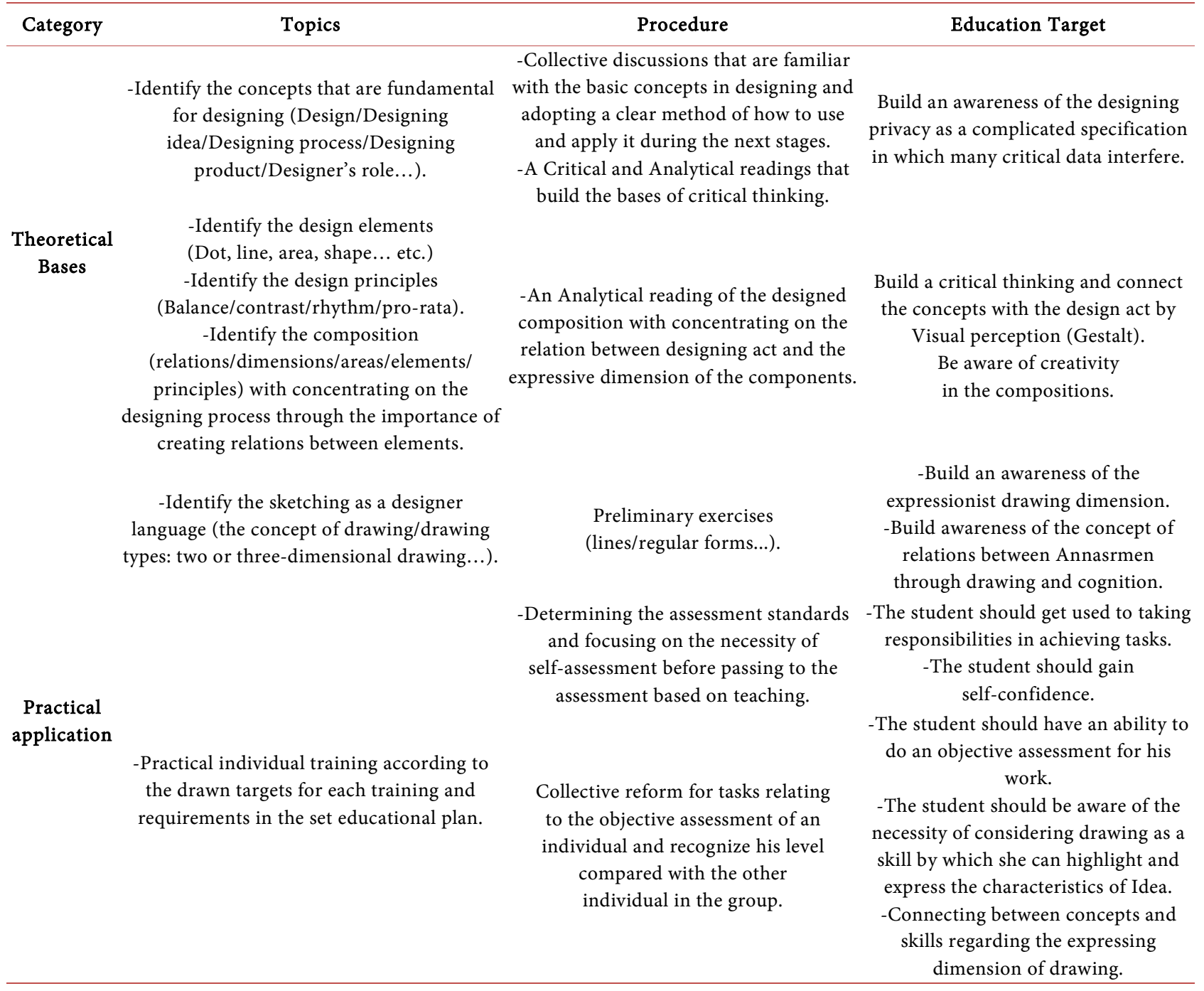

Table 2. Steps of foundation stage.

\begin{tabular}{|c|c|c|c|c|c|}
\hline $\begin{array}{l}\text { Plan } \\
\text { Stages }\end{array}$ & Period & $\begin{array}{c}\text { Presented } \\
\text { Academic } \\
\text { Material }\end{array}$ & Training & $\begin{array}{l}\text { Self-assessment } \\
\text { standards }\end{array}$ & Educational targets \\
\hline 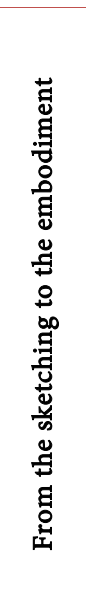 & $\begin{array}{l}\text { First Week } \\
8 \text { hours }\end{array}$ & $\begin{array}{c}\text { Elements and } \\
\text { Principles } \\
\text { of design }\end{array}$ & $\begin{array}{c}\text { Practical practice 1: } \\
\text { Instructions } \\
\text {-Determine two elements of design: Dot and Line } \\
\text {-Choose a principle of design } \\
\text {-Build two-dimensional composition in an area } \\
\text { Requirements } \\
\text { cm } \\
\text { Train on design composition by using evaluation } \\
\text { standards in order to be able to express a principle } \\
\text { determined from the start of design } \\
\text { according to steps determined in Figure } 1 \\
\text {-All what has been expressed to } \\
\text { re-start the design with a new principle. } \\
\text { Goal } \\
\text { Reach the determined principle by use } \\
\text { the elements of developing drawing skills. }\end{array}$ & $\begin{array}{l}\text {-Use intensity for } \\
\text { dot/line } \\
\text {-Change font for } \\
\text { dot/line } \\
\text {-A Pro-rata in building } \\
\text { relation in composition } \\
\text {-Expressive dimension } \\
\text { of composition } \\
\text {-The response to the } \\
\text { principle determined } \\
\text { since the start of design } \\
\text { by use elements and } \\
\text { accuracy for standards. }\end{array}$ & $\begin{array}{l}\text { Start the expertise of design } \\
\text { from initial concepts and } \\
\text { knowledge } \\
\text {-Recognize difficulties between } \\
\text { determining choices and } \\
\text { expressing them based on the } \\
\text { drawing } \\
\text {-Train on building design } \\
\text { relations from a certain goal } \\
\text { and principle } \\
\text {-Enable the student from } \\
\text { gaining gradual skills and } \\
\text { knowledge }\end{array}$ \\
\hline
\end{tabular}




\section{Practical practice 2: Instructions}

Third week Design between 5 hours sketching and embodiment -Inspiration Requirements week nature/living 6 hours nature -the design methods steps Figure 1.

\section{Goals}

Workshop:

Instructions
-Choose a picture of silent nature/living nature. -Abstract the picture and get its fine bases.

-Define a method of design methods.

-Build 2 dimensional compositions with $7 \times 7 \mathrm{~cm}$

from Training design compositions by using the picture Second the silent as an inspiration source and the standards as a reference to evaluate the extent of expressing method, which defined at the beginning of the design process, in accordance with the defined

-express the necessary method of re-design process by new method.

How to express the defined method by using a picture as an inspiration. Improve and develop the drawing skills.

-Choose one of compositions that have been com pleted and exercised during the past practices.

-Use the shadow technique on an area of $7 \times 7 \mathrm{~cm}$, to determine plenum and emptiness' area.

-Enlarging the shadowed composition on an area of $14 \times 14 \mathrm{~cm}$, and drawing it on a pressed cork in order to use the

\section{Goals}

-Control time.

-The ability to depict an idea of a design. -Acquisition of embodiment skills. Outputs

-Delivering a shadowed composition on an area of $7 \times 7 \mathrm{~cm}$

-A hollow composition on an area of $14 \times 14 \mathrm{~cm}$. discharge technique to express the idea.
Choosing composition and design.

-Clarity in forming design relations therein (Pro-rata.)

-Harmony of shadow with the idea of design "Expressing the design." -Quality of implementation "Implementation of the design."
-Perceiving the concept of building design relations, starting from embodiment.

-Establishing a relation

between drawings to express ideas and design outcomes-Embodiment of an idea.

-Noting the necessity of lines, spaces and relations in drawing and the expressive dimension concept for compositions.

-Start the expertise of design from deep concepts and knowledge based on special experience

Practical practice3: Instructions

Approve practical practice $1 \& 2$.

Build two-dimensional

compositions in areas $7 / 7 \mathrm{~cm}$

Requirements

Fourth

Week

6 hours approve during the practical practice 2 .
The same standards
The same requirement during practical practice $1 \& 2$ Goals

-Be able to manage the design in a more effective manner and self-confidence

-Develop and improve fine arts and

build relations between the design elements Improve and develop drawing skills
-Hold extensive training based on design relation

beginning from a method, principle after the embodiment of plenum and vacuum

-Develop visual cognitive abilities for relation between the analytical reading and design (Gestalt)

-Enable the student from gaining skills and knowledge with self-confidence beginning from binding concepts with drawing. 
Table 3. Taking notes and document the outputs.

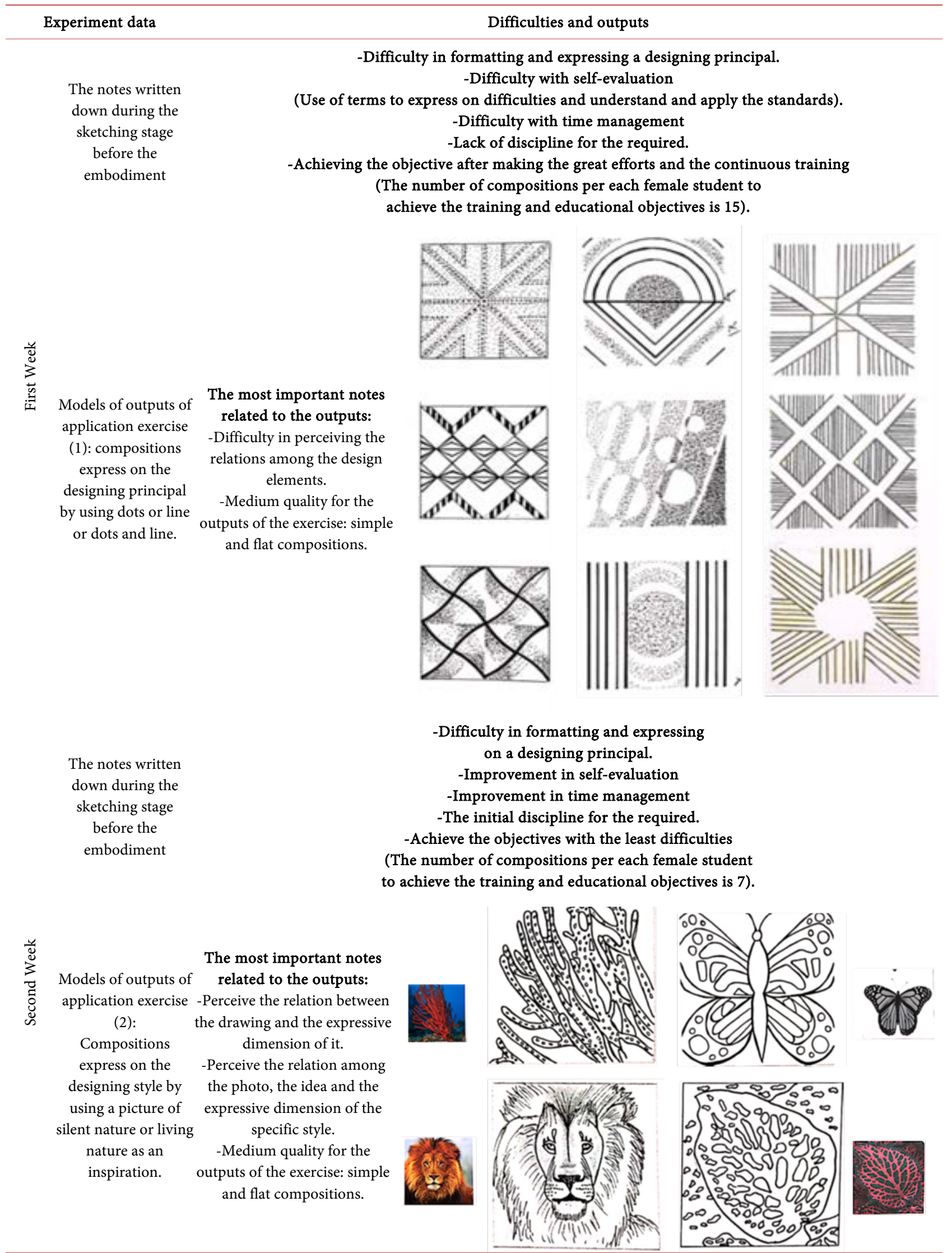


The notes written down during the stage between the sketching and the embodiment

Models from workshop's outputs: Embodied compositions express on the design style

Embodiment

(cutting paper template)/Sketching
The notes written down during the sketching stage after the embodiment

-Understanding all the main concepts of the design (Elements, principles, styles, etc.)

-Awareness of the importance of plenum and vacuum, in addition, the necessity for reviewing the compositions drawn after the embodiment. -Objectivity of evaluation according to the standards.

-Remarkable improvement in time management.

-The positive exceeding of the required, the ability to innovate and excel for most of the female students by the use of different materials and complex compositions.

-Achieving the objective with the least difficulties, besides the Enjoyment and self-confidence (the number of solids per each female student to achieve the training and educational objectives is 3 ).

The most important notes related to the outputs:

-Reflect the logic of link the relation between shading and carving

-High quality of the design, sketching drawing, and carving: compositions express on the principal or style of design.

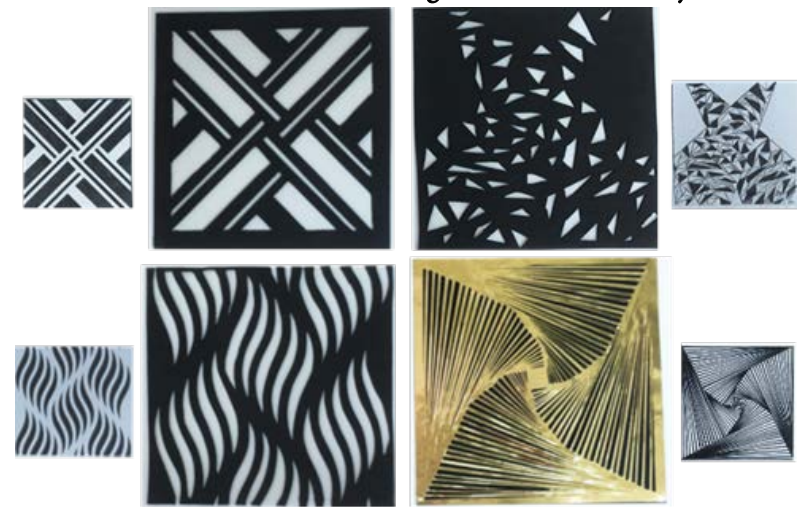

-The ease and speed in formatting and expressing on the principal and style of design. -Perceive the relation between the drawing and the expressive dimension of it.

-Take the responsibility and depend on self-evaluation

-Great improvement in time management -Reconsider the initial compositions and the full discipline for the required. -Achieve the objective easily and with self-confidence

(the number of compositions per each female student to achieve the training and educational objectives is 2).

The most important notes related to the outputs:

outputs resulting from the reconsideration of application exercise

(1) and (2):

Compositions express on the principal and style of design by the use of a reference idea.

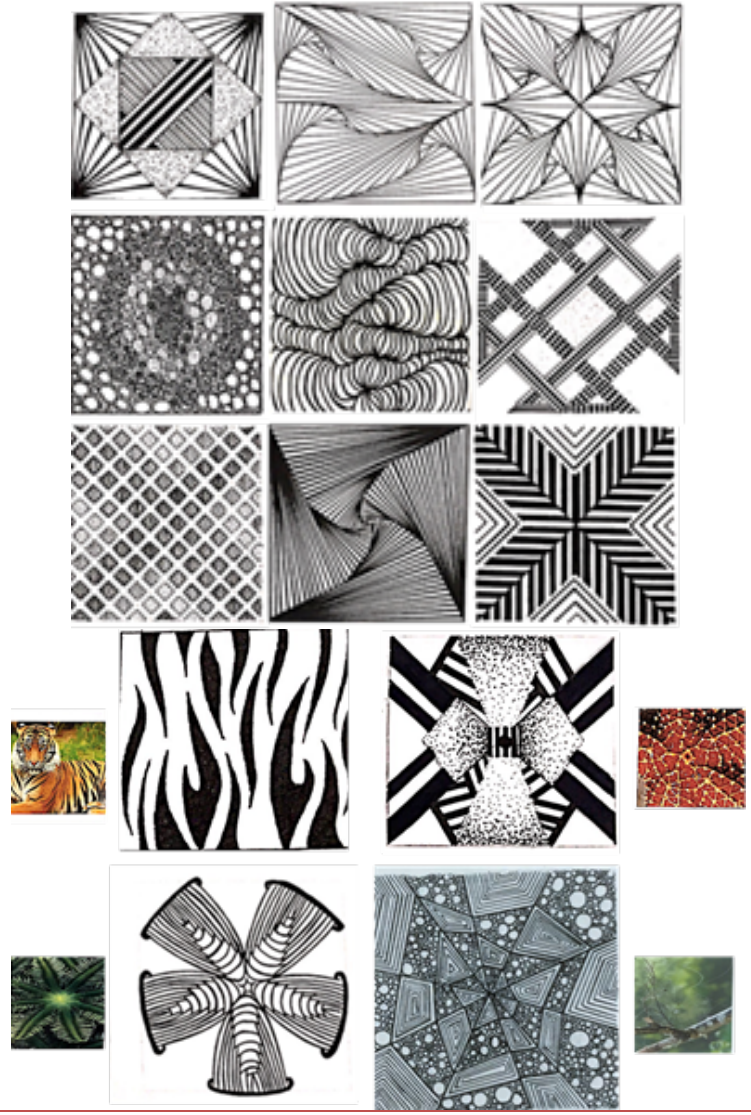




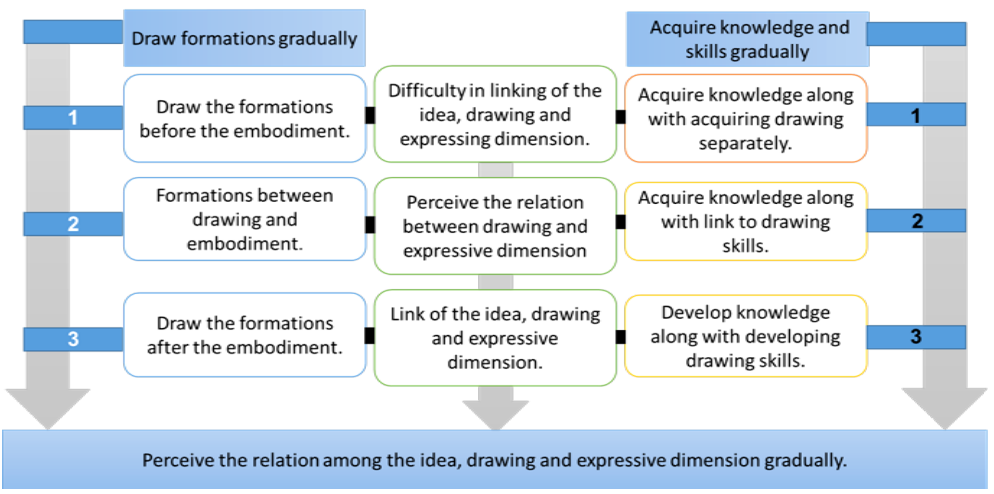

Figure 2. The proposed teaching strategy to facilitate the perception of the relations between the designing idea and bases of its projection in the foundation stage.

The researcher reports the most important difficulties in the follow-up of the students, when they conduct this experience with following sequences.

Difficulties basically are as follows:

- Formatting and expressing on the principle or style of design.

- Perceiving the relation resulting from the space, area, and shape during sketching.

- Concentrating on more than one element at the same time (the drawn elements/defined choices/resulted spaces and shapes/harmony and proportion).

The main contribution of this research is to clarify the importance of teaching strategy based on drawing formations and acquiring knowledge and skills gradually and in parallel. This strategy was defined to overcome difficulties in Figure 2.

From this perspective, the researcher has suggested a teaching strategy that will make the student able to perceive the relations between an idea and foundations of projection in the foundation stage of the design filed generally and the interior design specially. This proposal is represented in three main consecutive steps, in which the grading of acquiring the knowledge and skills is parallel to the grading of perceiving the concept of building the relations among the elements of design.

These steps cannot be considered independently. It made the student acquire the conceptual relation related to the conformity of the data of three-dimensional drawings to the expressive dimension of the design's idea. This conceptual relation made students to project their design's ideas easily, and perceive the major importance of building relationships between the design's idea and foundations of their projections.

The last step, specially, made the student able to perceive the concept of building the relations among the elements of design, sketching after the embodiment, including overcoming the difficulties in linking of the idea, drawing and expressive dimension of the idea.

\section{Conclusion}

The proposed strategy in teaching bases of design to perceive the relation be- 
tween an idea and foundations of projection expresses on a private experiment by which specific elements were chosen among a set of different elements of design, reference to the possibility of conducting other experiments with the same methodology and different chosen elements (such as choosing shapes and spaces). The proposed steps of the sketching before, during and after the embodiment remain the basis of the educational process, even if the specified elements are different. In addition, it's necessary to adopt the self-assessment as the basis in the educational process, which let the students depend on reference standards that make them able to create their own vision gradually.

The strategies of teaching students how to design formations and build relations between design elements in the foundation stage is considered the most important strategy in terms of construction and results and they require special care and the efficiency of those who are in charge of it. In this context, the researcher suggests that these strategies should receive special attention to the importance of this stage in building the student's vision as he is recognized as the designer of the future.

In this regard, the scope of the proposed strategies experiment can be expanded through diversification of the design elements used in the exercise data, and change the proposal of the two points of dot and line such as diversification in using shapes, texture and colors. However, the necessity to adopt two elements and no more is still the strong point of the proposed strategy so as to enable linking the first step requirements with the second step in particular, and activating the embodiment of plenum in its relation to the first used element and vacuum in its relation to the second element.

Study sample and number can also be expanded to other samples vary according to cultural and social circles in order to know the extent of the influence of the cultural environment on the graphic aspect in design. What can be noted in this study limitation is the long time the experiment took (19 hours in total) to achieve the indicated educational targets while it is supposed not to exceed 12 hours in total. That may be due to the failure to devote special attention to graphic culture generally in the cultural context relevant to the selected sample.

The proposed strategy can turn student passive attitude into student active attitude and help them to be confident, creative and so fonder. But it will be important to deepen research on student needs, especially, on teaching strategy related to how to orient students to make choice and decision on designing by themselves in advantage stages, and how to empower them to acquire knowledge and skills in any design education stage.

\section{Acknowledgements}

I'm grateful for the generosity of my colleagues whose instruction and advice were helpful in setting the focus of my discussion. Further, I would like to acknowledge all of my students at Faculty of Home Economics at King Abdul-Aziz University in Jeddah, Saudi Arabia, to give me the opportunity to apply this study. I also offer special thanks to the editor for his clear eye and useful comments for improving this paper. 


\section{References}

Gencosmanoglu, A. B., Engin, E., \& Aydintan, E. (2011). First Term Interior Design Studio as a Process of Teaching, Learning and Expressing. Scientific Research and Essays, 6, 3461-3473.

Orthel, B. D., \& Day, J. K. (2016). Processing Beyond Drawing: A Case Study Exploring Ideation for Teaching Design. SAGE Open, 6.

Tavsan, F., \& Sonmez, E. (2012). Search for a New Teaching Model in Interior Architecture Education; Abstraction through Body Language and Drawings in Furniture History Course. Procedia-Social and Behavioral Sciences, 46, 2669-2674.

Ustaomeroglu, A. A. (2015). Concept-Interpretation-Product in Architectural Design Studios-Karadeniz Technical Universty 2nd Semester Sample. Procedia-Social and Behavioral Sciences, 197, 1897-1906.

Ustaomeroglu, A. A., Aydintan, E., Erbay, M., Kucuk, P., \& Sadiklar, Z. (2015). The Impact of Basic Design Studio Courses on Interior Design: KTU Model. Procedia-Social and Behavioral Sciences, 197, 1889-1896.

Wang, T. (2010). A New Paradigm for Design Studio Education. JADE, 29, 173-183.

Zaytoun, K. A. (2000). Teaching-Models and Skills. Alexandria: Scientific Publication and Distribution Office.

Submit or recommend next manuscript to SCIRP and we will provide best service for you:

Accepting pre-submission inquiries through Email, Facebook, LinkedIn, Twitter, etc. A wide selection of journals (inclusive of 9 subjects, more than 200 journals)

Providing 24-hour high-quality service

User-friendly online submission system

Fair and swift peer-review system

Efficient typesetting and proofreading procedure

Display of the result of downloads and visits, as well as the number of cited articles

Maximum dissemination of your research work

Submit your manuscript at: http://papersubmission.scirp.org/

Or contact adr@scirp.org 